\title{
sciendo
}

10.2478/aucft-2021-0007

\section{EVALUATION OF CRYSTALLINE CELLULOSE OF CORN STRAW THROUGH DIFFERENT PRETREATMENTS VIA X-RAY DIFFRACTION, SCANNING ELECTRON MICROSCOPY AND INFRARED SPECTROSCOPY}

- Research paper -

\author{
He CHEN"1, Chun YIN*, Wenfei SHANGGUAN* ${ }^{*}$, Yunxia HE*Li CHEN*1, Jianjun YU** \\ ${ }^{1}$ School of Food and Biological Engineering, Shaanxi University of Science and Technology, Xi'an \\ 710021, China \\ **College of Food Engineering and Nutritional Science, Shaanxi Normal University, Xi'an 710119, \\ P. R. China.
}

\begin{abstract}
Waste recycling is beneficial not only for the environment but also for the economy and the society at large. Corn stalks, the most abundant crop waste, are processed with oven drying, steaming, complex enzymatic hydrolysis (cellulase, xylanase, $\beta$-glucanase and pectinase), and fermentation (by Candida utilis and Pachysolen tannophilus), were analyzed via X-ray diffraction, Scanning Electron Microscopy (SEM) and Infrared Spectroscopy (IR). The results indicated that thermophilic digestion destroyed glycosidic bonds and fibrous crystal have a significant effect on the degradation of the corn stalks, while complex enzyme hydrolysis only slightly degraded fibrous crystal. Fermentation did not significantly reduce fibrous crystal. Therefore, our research suggested that thermophilic digestion is the appropriate way to increase the saccharification rate and feed yield of corn stalks.
\end{abstract}

Keywords: Corn stalk; X-ray diffraction; Fibrous crystal; SEM and IR

\section{INTRODUCTION}

Nowadays, the circular economy (CE) is a development model which solves the international contradictions of the socio-economic development and ecological environmental protection. Compared with the traditional linear models, the $\mathrm{CE}$ model's core tenet requires to maintain the added value in products as long as possible and minimize waste, which can create more value from each unit of resource. Corn stalk is the most abundant agricultural waste in China, whose maximum output reached to 239 million tons in 2017. Conversing corn stalk into biofuels (biochar, bio-oil, and gas) is a sustainable way in recycling biomass, which will not transfer harmful effects in the future but also benefit to spread environmental protection in CE model.

The corn stalk is composed of $29.80 \%$ of cellulose, $33.30 \%$ of hemicellulose, $16.65 \%$ of lignin, $8.5 \%$ of ash and $11.75 \%$ of others materials (Shawky et

Received: 15.01.2021

Accepted in revised form: 11.02 .2021 al., 2011). After pretreatment and enzymatic hydrolysis, straws can be used to produce foodgrade glucose, single-cell protein, xylooligosaccharides, lactic acid and other food additives and functional ingredients (Wang et al., 2018). Because of its large amount of crystalline cellulose, it is difficult to degrade corn stalk by enzymatic preparation (Su et al., 2006; Wyman and Yang 2009). Therefore, pretreatments of corn stalks have a vital influence on utilization process, which can remove the lignin and hemicellulose and reduce the crystallinity of cellulose. Numerous pretreatments methods of corn stalk have been reported, but few people pay attention to the crystallinity of crystalline cellulose (Behera et al., 2014; Rastogi et al., 2017; Hassan et al.,2018; Huang et al,2018; Kojima et al.,2019; Ponnusamy et al.,2019; Xu et al.,2019)

The study compared of four pretreatments methods that is oven drying, steaming, complex enzymolysis and fermentation by Candida utilis and Pachysolen tannophilus, evaluating the

${ }^{1}$ Corresponding authors. E-Mail address: chenhe419@gmail.com , chenlisp@ snnu.edu.cn 
crystallinity of crystalline cellulose after treated with the aid of X-ray diffraction, scanning electron microscopy and infrared spectroscopy. At the same time, the corn stalks's utilization rate of reducing sugar and the output of protein feed have been increased (Chen and Zhang, 2008; Luo et al., 2009;

\section{MATERIALS AND METHODS}

Oven-dried corn stalks and steamed corn stalks Fresh green corn stalks harvested from the Weiyang District, Xi'an City, Shaanxi Province in China, which were passed through a 40-mesh sieve and then dried at $60{ }^{\circ} \mathrm{C}$.

The stalk powder, which was passed through a 40mesh sieve, was cooked for $1.5 \mathrm{~h}$ at $180{ }^{\circ} \mathrm{C}$ and then dried at $60{ }^{\circ} \mathrm{C}$.

\section{Enzymatic hydrolyzed corn stalks}

The $0.6144 \mathrm{~g}$ steamed corn stalks was added to $30 \mathrm{~mL}$ of citric acid buffer with $\mathrm{pH} 4.8$, and then hydrolyzed at $50^{\circ} \mathrm{C}$ at a speed of $100 \mathrm{rpm}$ for $16 \mathrm{~h}$. The obtained residue was dried at $60{ }^{\circ} \mathrm{C}$. The complex enzyme was consisted of $20 \mathrm{mg}$ of cellulase, $10 \mathrm{mg}$ of xylanase, $6 \mathrm{mg}$ of $\beta$-glucanase and $1.3 \mathrm{mg}$ of pectinase.

\section{Fermented corn stalks}

After fermentation and degradation transformation, corn stalks underwent complex enzymatic hydrolysis by using two strains (Candida utilis and Pachysolen tannophilus).

The sediment was centrifuged at 3500rpm and dried at $60{ }^{\circ} \mathrm{C}$. Overall, $100.0 \mathrm{~g}$ of oven-dried stalks could be converted into $83.42 \mathrm{~g}$ of thermophilical digested stalks, $64.82 \mathrm{~g}$ of enzymatical hydrolyzed stalks and $82.04 \mathrm{~g}$ of fermented stalks.

\section{Determination of composition content of corn stalk}

The main lignocellulosic fractions of cellulose, hemicellulose, lignin and ash in the sample were determined with the following protocol (Soest et al.2016; Wang and $\mathrm{Xu}$ 1987)50 $\mathrm{mL}$ of neutral detergent mixed with $0.5000 \mathrm{~g}$ samples was kept in a $100{ }^{\circ} \mathrm{C}$ autoclave for $1 \mathrm{~h}$ and filtered through a No.3 sand core funnel till that the solution of sample was neutral. Discard the filtrate A. The residue $\mathrm{A}$, which was washed twice with acetone, was transferred to a $50 \mathrm{~mL}$ colorimetric tube which was added into $50 \mathrm{~mL}$ of $2 \mathrm{~mol} \cdot \mathrm{L}-1$ hydrochloric acid solution. Then the mixture, which was kept at $100{ }^{\circ} \mathrm{C}$ for $50 \mathrm{~min}$, was filtered
Chen et al., 2009; Yang et al., 2015; Wu et al., 2016; Chen et al., 2018). Thus, comparing the structure of fibrous crystal and crystallinity can provide certain theory reference for improving the high utilization rate of corn stalk.

with No.3 sand core funnel. Finally, filtrate B and residue $\mathrm{B}$ are obtained.

The filtrate B was appropriately diluted. Add $5 \mathrm{~mL}$ of orcinol reagent to $1 \mathrm{~mL}$ of filtrate $B$. The mixture was kept at $100{ }^{\circ} \mathrm{C}$ for $20 \mathrm{~min}$ and then the OD value was measured at $660 \mathrm{~nm}$. The content of hemicellulose was obtained by a factor of 0.9 multiplying the amount of sugar which was determined according to the xylose standard curve. The residue B was adjusted to pH6.5-7.0 with water rinsing and washed twice with acetone and then dried at $60{ }^{\circ} \mathrm{C}$. Added $5 \mathrm{~mL}$ of $72 \% \mathrm{H}_{2} \mathrm{SO}_{4}$ and hydrolyzed at $20{ }^{\circ} \mathrm{C}$ for 3 hours. After hydrolyzation, $45 \mathrm{~mL}$ of water was added. The mixture, which left overnight at room temperature, was filtered with a constant weight G2 sand core at the next day. Finally,obtained filtrate $\mathrm{C}$ and residue $\mathrm{C}$.

The filtrate $\mathrm{C}$ was appropriately diluted. Add $4 \mathrm{~mL}$ of anthrone reagent to $1 \mathrm{~mL}$ of the filtrate $\mathrm{C}$. The mixture was kept at $100{ }^{\circ} \mathrm{C}$ for $10 \mathrm{~min}$ and then the $\mathrm{OD}$ of the mixture was measured at $620 \mathrm{~nm}$. The content of cellulose was obtained by a factor of 0.9 multiplying the amount of sugar which was determined according to the glucose standard curve.

The residue $\mathrm{C}$, which was dried at $80{ }^{\circ} \mathrm{C}$, was weighed (W) and then ashed at $550{ }^{\circ} \mathrm{C}$ to obtain the weight of ash (W1). Therefore, the content of lignin is W-funnel weight - W1.

The content of crude protein was determined with Micro Kjeldahl Method (Stafilov et al, 2020).

\section{Analyses of corn stalks by X-ray diffraction}

A Rigaku D/Max 2200 PC (Rigaku Corporation, Tokyo, Japan) diffraction instrument was used for the $\mathrm{x}$-ray diffraction analysis. The condition was showed as following: graphite monochromatic dish, $\mathrm{CuK} \alpha$ radiation, wavelength $\lambda=0.154056 \mathrm{~nm}$; accelerative field $40 \mathrm{KV}$; electric current $40 \mathrm{~mA}$; scanning step $0.02^{\circ}$; Range $5^{\circ}$ to $60^{\circ}$.

An atlas analysis was done using smooth processing with MDI Jade 5.0 software (Materials Data, Inc., Livermore, USA) and multi-peakresolution fitting.

The interplanar distance, $d$, was calculated using the Bragg equation, as shown in Eq. 1: 
$2 d \sin \theta=n \lambda$

(1)

where $d$ is the interplanar distance (A), $\theta$ is the angle of incidence $\left(^{\circ}\right), \mathrm{n}$ is an integer (set at 1 in this case), and $\lambda$ is the wavelength (nm).

The mean crystalline size was calculated using the Scherrer equation, as shown in Eq. 2:

$D=K \lambda / B 1 / 2 \cos \theta$

where $\mathrm{D}$ is the mean size of the microcrystalline $(\mathrm{nm}), \mathrm{K}$ denotes a constant (set at 1 in this case), $\lambda$ is the wavelength (nm), and B1/2 denotes the full width at half maximum (FWHM) of the diffraction peaks $\left({ }^{\circ}\right)$.

The crystallinity was calculated according to Eq. 3: $S \alpha / S \beta \times 100 \%$

where $S \alpha$ is the total area of integral strength of the crystallization peak and $S \beta$ is the total area of the whole line.

\section{RESULTS AND DISCUSSIONS}

\section{Effect of different pretreatment on the compositions of corn stalks}

The regression equation standard curve of xylose by orcinol hydrochloric acid method is showed as
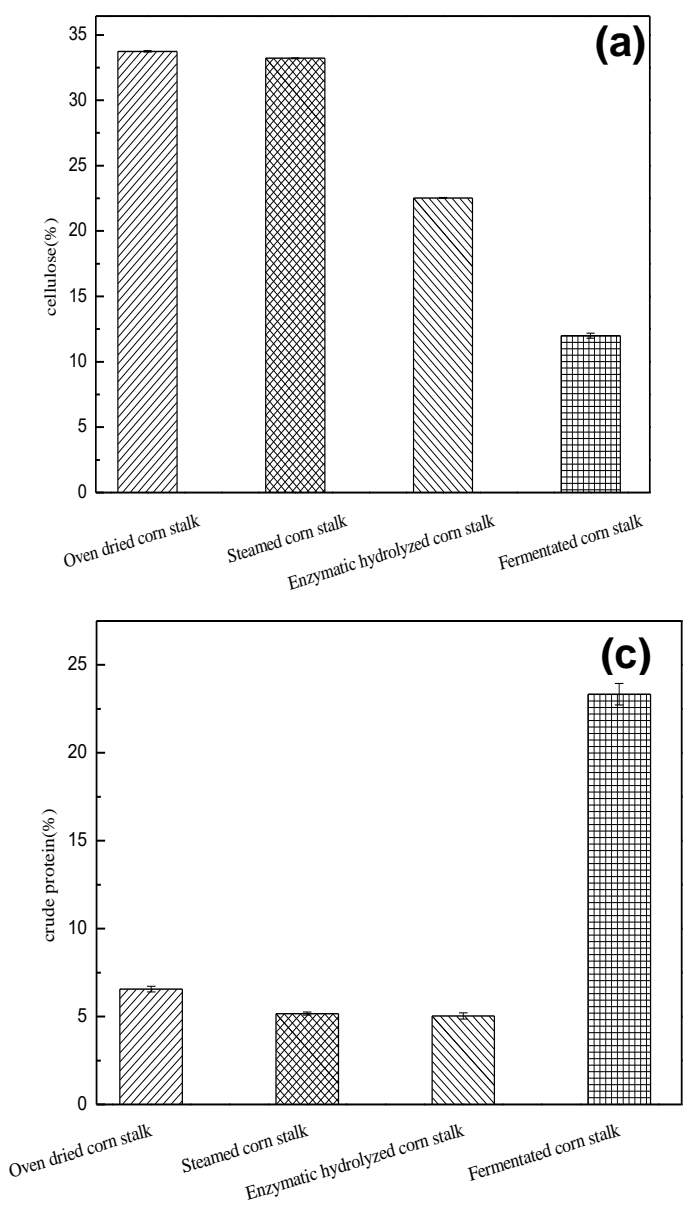

\section{Imaging analyses by SEM and IR:}

Corn stalks with pretreatment were examined by using Mini SEM Scanning Electron Microscopy). Changes of microstructure and morphology were analysed by using SNE-3000M microscope (Korea Seco Co., Ltd.). The dried corn stalks were mounted on sample stubs and coated with platinum by using an ion sputter coater. For each sample, SEM photos were taken in three different magnifications of $0.5 \mathrm{~K}$ and $1 \mathrm{~K}$. IR spectra were recorded using Fourier Infrared Spectrometer VECTOR-22; Bruker Optics Inc., Germany). The spectra were obtained in the transmission mode and the range of $400-4000 \mathrm{~cm}^{-1}$ at a resolution of $4 \mathrm{~cm}^{-1}$ with 32 scans per each sample.

$y=0.0018 x+0.008$. In the meantime, the standard curve of glucose by anthrone colorimetry is showed as $\mathrm{y}=0.0075 \mathrm{x}+0.0763$.

Effects of different pretreatment on the different constituents' content of corn stalks were shown in Figure 1.
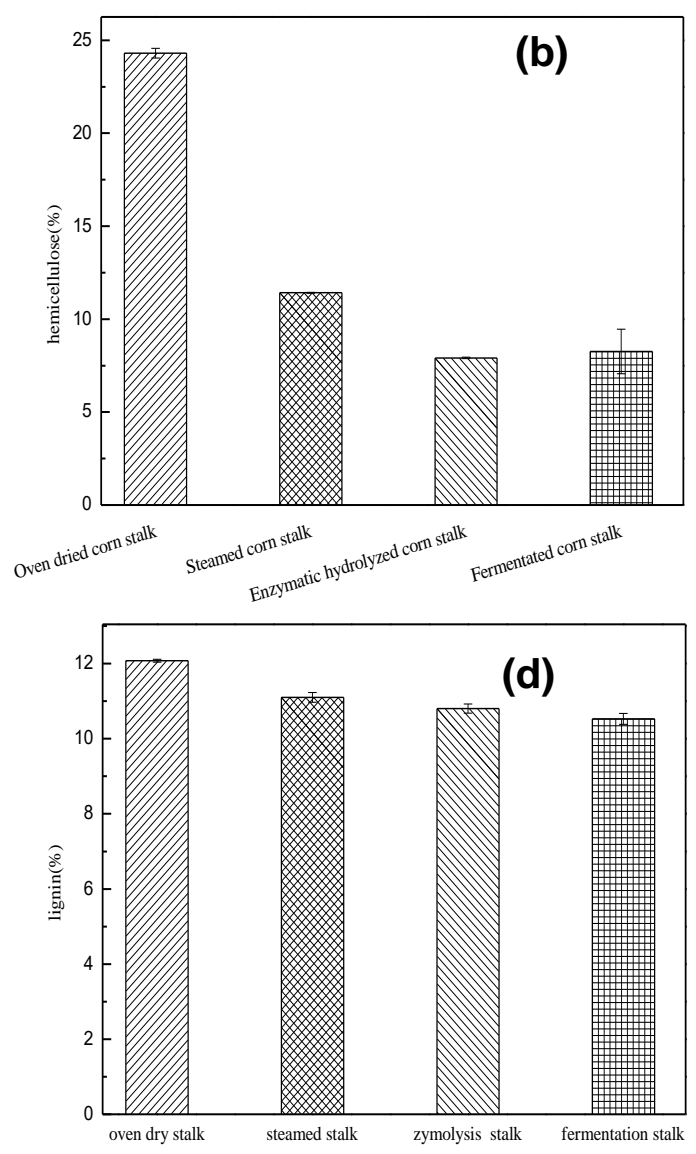

Figure 1. Main components contents of processed corn stalk (\%) 
Compared with oven-dried corn stalks, cellulose of steamed corn stalks decreased by about $0.5 \%$. High temperature of $180^{\circ} \mathrm{C}$ had no effect on cellulose degradation. On the contrary, cellulose degradation of corn stalks by enzymatic hydrolysis and fermentation was significant. The cellulose content of fermented stalks was nearly half less than that content of enzymatic ones for $16 \mathrm{~h}$. The cellulose composition is consisted of nonenzymatic cellulose and yeast cellulose. The hemicellulose content of steamed corn stalks decreased obviously, which indicated that high temperature had a significant effect on hemicellulose degradation. The hemicellulose content of fermented corn stalks was slightly more than that content of enzymatic one which was supposed to be nonenzymatic hemicellulose and pentose polymers in yeast. The contents of crude protein of fermented corn stalks was higher than other pretreated corn stalks. Four pretreatments had a limited significant effects on ash and lignin degradation.

\section{Effect of different pretreated on corn stalks during the $X$-ray diffraction analysis}

Effects of four different pretreatments on corn stalks during the X-ray diffraction atlases were shown in Figure 2. The crystallinity of cellulose
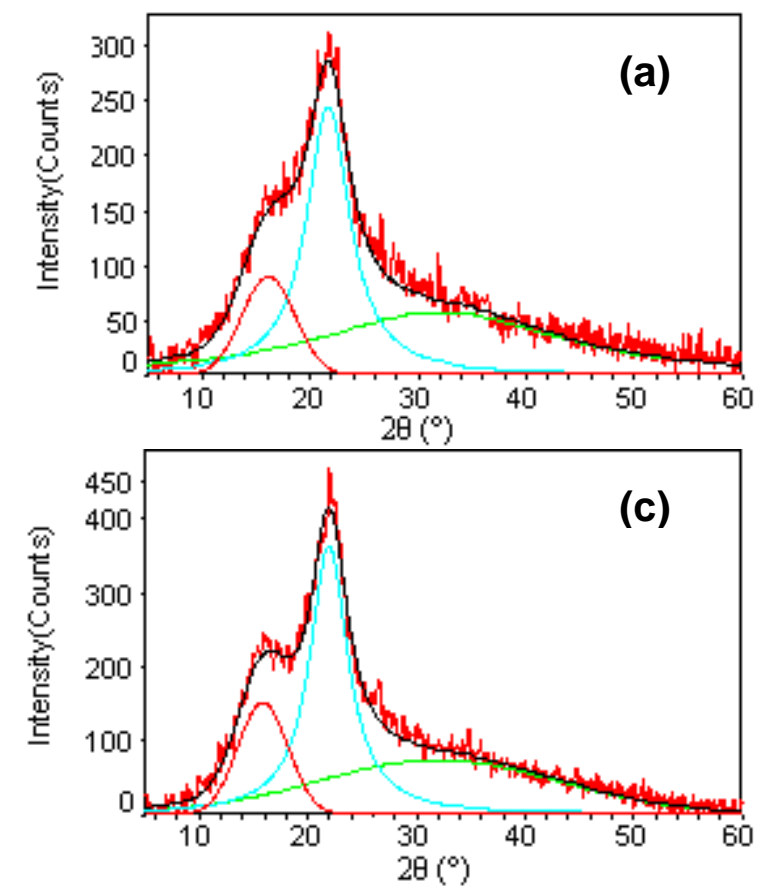

was well described by the x-ray diffraction atlas. As showed in Fig. 2, there were two main diffraction peaks of cellulose. One of the peaks was located at $2 \theta$ from $15.8^{\circ}$ to $16.3^{\circ}$ which corresponded to crystal surface 101 in the cellulose crystal. The other peak was located at $2 \theta$ from $21.6^{\circ}$ to $22.0^{\circ}$ which corresponded to crystal surface 002. However, others were too small to give useful information. This crystal type belonged to cellulose I which was natural cellulose. The changes of types were not affected during the pretreatment. The third fitted peak was a noncrystallization peak. Its half peak width was large, which was the result of the comprehensive effects of other amorphous molecules.

The related information obtained from the atlases is shown in Table 1. There were slight differences in the position of the diffraction peaks of the same crystal plane among pretreated corn stalks. It probably could be explained by the composition of the cellulose and peak shift caused by other components. However, d was inversely proportional to $\sin \theta$, and $\theta$ were all in the range between 21.662 and 21.981 which differences were small. Therefore, the d-value of the same crystal plane remained. The FWHM was determined by the grain size. The smaller the grain size was, the larger the FWHM.
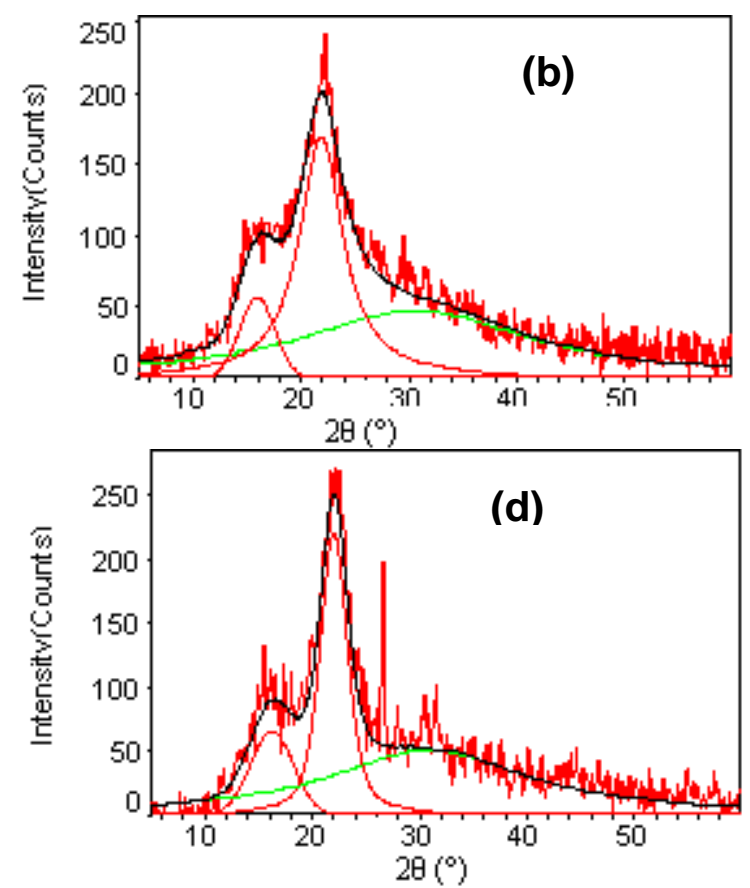

Figure 2. X-ray diffraction analysis of stalks processed with various methods (a: oven-drying, b: steaming, c: enzymolysis, and d: fermentation) 
There was a noticeable change in the two diffraction peaks, as shown in Table 1 . The micro crystallite that was perpendicular to the 101 direction of the crystal surface increased in size. There was no clear regularity, which could only explain the changes in the composition of cellulose. The change in the size of the crystallite that was perpendicular to the 002 direction of the crystal surface which was relatively regula. The smaller the size of the cellulose was, the more easily it degraded. This result might have caused by cellulase enzymolysis, which made the ratio of the small fibrous crystal to big fibrous crystal smaller, resulting in an increase in the mean size of the microcrystallite. The mass of the stalks changed as a result of the different steps of pretreatments, so the changes in the cellulose crystallinity of differently processed stalks could not be directly compared. The corresponding conversion: the crystallinity of cellulose accounted for oven-dry stalk at any given time point $=$ crystallinity $x$ the mass of the stalk in that processing / the mass of the oven-dry stalk before conversion. The results after conversion are shown in Table 2.
As shown in Table 2, the cellulose crystallinity declined. As a result of thermophilic digestion, the cellulose crystallinity decreased by nearly onethird, indicating that thermophilic digestion had a large destructive effect on the cellulose crystallinity. However, the enzymatic hydrolysis for $16 \mathrm{~h}$ had minimal damaging effect on the cellulose crystallinity, which suggested that the cellulase did not substantially degrade the fibrous crystal. The cellulose crystallinity of the fermented corn stalks decreased by $3 \%$. This result indicated that the fibrous crystal was difficult to degrade. However, it was also possible that the cellulose in the cytoderm generated by the yeast had crystallinity, resulting in the cellulose crystallinity being maintained at $22.58 \%$. Instant catapult steam explosion was used to pretreat corn stalks, the crystallinity of corn stalks dropped significantly by 43.5\% (Ma et al., 2018), which is consistent with our research.

\section{Imaging of corn stalks by SEM and FTIR}

The imagings of corn stalks by SEM and FTIR are shown in Figures 3 and 4 . The summary of function of each wavelength in FTIR of four pretreated corn stalks is shown in Table 3.

Table 1. Information on X-Ray Diffraction Patterns of Stalks with different pretreatment

\begin{tabular}{|c|c|c|c|c|c|c|c|}
\hline $\begin{array}{l}\text { Stalk Processing } \\
\text { Method }\end{array}$ & $\begin{array}{l}\text { Diffraction Peak of } \\
\text { Crystal Plane }\end{array}$ & $\begin{array}{l}2 \theta \\
\left({ }^{\circ}\right)\end{array}$ & $\begin{array}{c}d \\
(\mathrm{~A})\end{array}$ & $\begin{array}{c}\text { FWHM } \\
\left({ }^{\circ}\right)\end{array}$ & $\begin{array}{c}\text { Strength } \\
\text { Area (a.u.) }\end{array}$ & $\begin{array}{l}\text { Crystallite } \\
\text { Size (A) }\end{array}$ & $\begin{array}{c}\text { Crystallinit } \\
\text { y (\%) }\end{array}$ \\
\hline \multirow[t]{2}{*}{ Oven-Drying } & $\begin{array}{l}\text { Diffraction Peak } \\
\text { (101) }\end{array}$ & 16.117 & 5.49 & 5.79 & 367.0 & 14 & 37.20 \\
\hline & $\begin{array}{l}\text { Diffraction Peak } \\
\qquad(002)\end{array}$ & 21.662 & 4.10 & 4.85 & 1166.6 & 17 & \\
\hline \multirow[t]{2}{*}{ Steaming } & $\begin{array}{l}\text { Diffraction Peak } \\
\text { (101) }\end{array}$ & 15.937 & 5.56 & 3.85 & 150.1 & 21 & 31.95 \\
\hline & $\begin{array}{l}\text { Diffraction Peak } \\
\text { (002) }\end{array}$ & 21.853 & 4.06 & 4.89 & 798.8 & 17 & \\
\hline \multirow[t]{2}{*}{ Enzymolysis } & $\begin{array}{l}\text { Diffraction Peak } \\
\text { (101) }\end{array}$ & 15.843 & 5.59 & 5.45 & 583.0 & 15 & 39.43 \\
\hline & $\begin{array}{l}\text { Diffraction Peak } \\
\qquad(002)\end{array}$ & 21.919 & 4.05 & 4.26 & 1534.2 & 19 & \\
\hline \multirow[t]{2}{*}{ Fermentation } & $\begin{array}{l}\text { Diffraction Peak } \\
\text { (101) }\end{array}$ & 16.228 & 5.46 & 4.72 & 214.3 & 17 & 27.52 \\
\hline & $\begin{array}{c}\text { Diffraction Peak } \\
(002)\end{array}$ & 21.981 & 4.04 & 3.05 & 559.7 & 27 & \\
\hline
\end{tabular}

*Note: FWHM- Full Width at Half Maximum

Table 2. Cellulose Crystallinity of pretreated_Stalks after Conversion (\%)

\begin{tabular}{ccccc}
\hline Crystallinity & Oven-dried Stalks & Steamed Stalks & $\begin{array}{c}\text { Enzymatically } \\
\text { Hydrolyzed Stalks }\end{array}$ & Fermented Stalks \\
\hline$(\%)$ & 37.20 & 26.65 & 25.56 & 22.58 \\
\hline
\end{tabular}


(a)
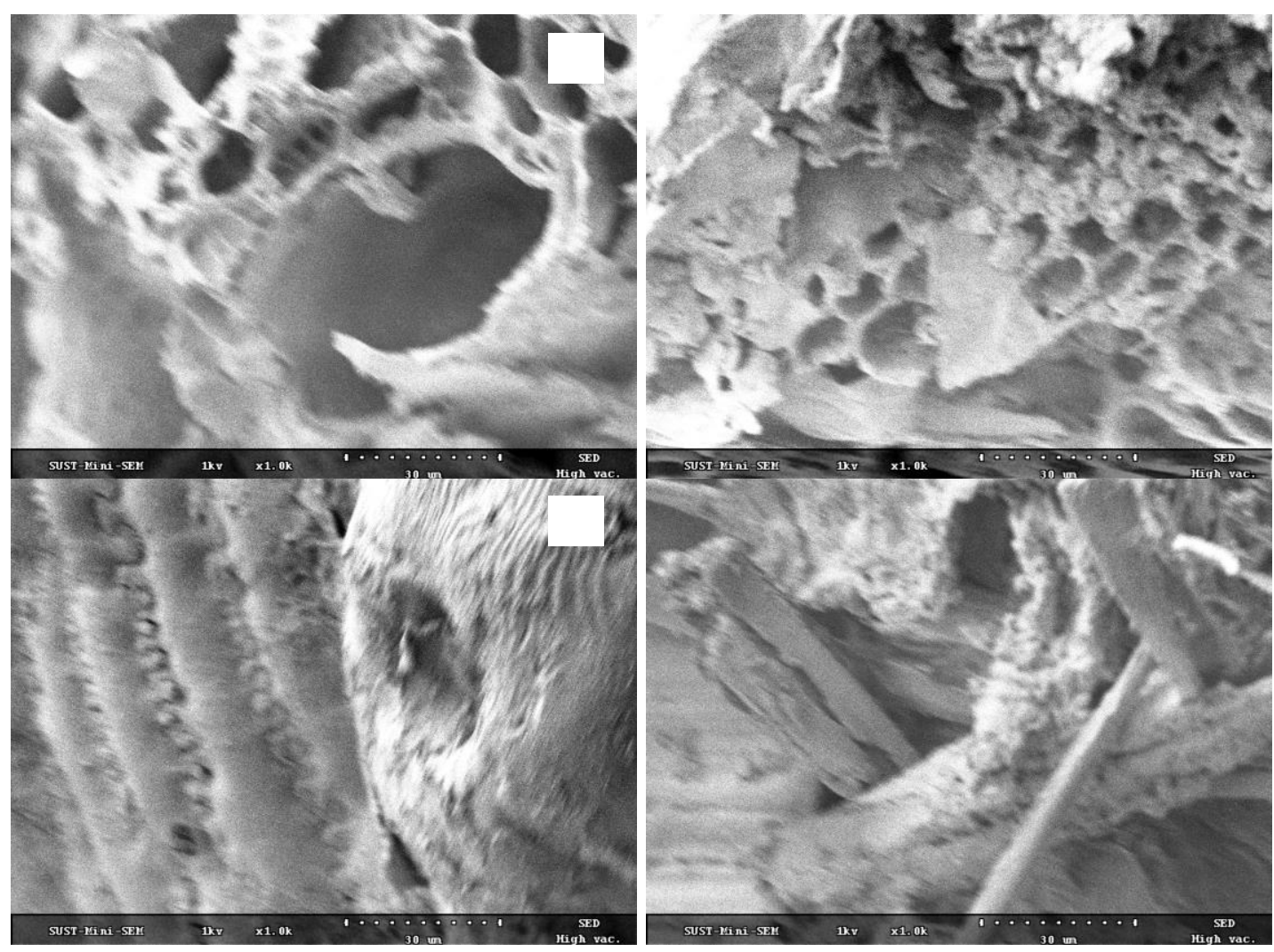

(b)

(c)

Figure 3. The SEM imaging of corn stalks by different process (a: oven-drying(x1.0k), b: steaming(x1.0k), c: enzymolysis(x1.0k), and d: fermentation(x1.0k))
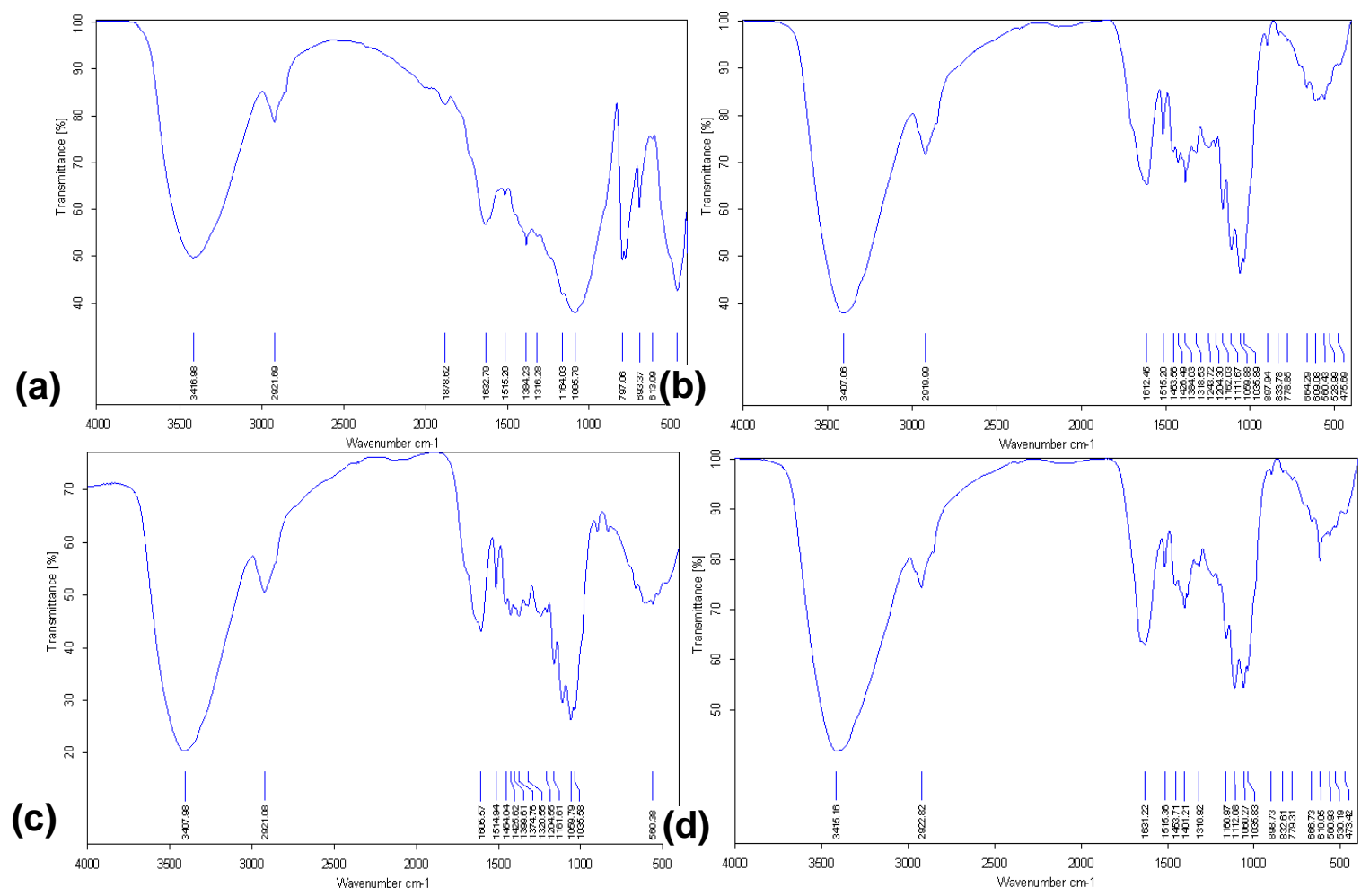

Figure 4. The Infrared spectra of corn stalks by different process (a: oven-drying, b: steaming, c: enzymolysis, and d: fermentation) 
The cross section and surface of oven-drying corn stalks are smooth and flat. The surface is almost free of pores and breakage (Figure 3a). The crosssection and surface of steamed corn stalks are very rough, while the surface appears to be severely damaged and has many pores (Figure 3b). However, the damaged small sheet surface is relatively flat and the edges are relatively regular, indicating that the high-temperature cooking has a strong damage to the corn stalk, increasing the specific surface area and contact area with enzyme. The surface of the enzymatic hydrolyzed corn stalks can be seen to be disjointed, and the surface of the recessed part on the right side of the picture (Figure 3c) is wool-like, and there are obviously filaments like wrinkles, indicating that the enzyme has a significant effect on the degradation of the corn stalks. As Figure 3d shows, some of the fermented corn stalks are not completely degraded and show as flakes, and the other surface is rotten like mud. The pores are very dense, which means that when fermentation corn stalks is in the simultaneous saccharification and fermentation process, the enzymolysis effect is reduced due to low temperature, which terminates fermentation. Some straws have not been completely digested. It is of great significance to allow the complex enzymes cellulase, xylanase, $\beta$ glucanase and pectinase to degrade for a certain period of time at its optimum temperature before fermentation.

It can be seen from the comparison of Figure 4 (a) and (b) that there is a large difference between the two spectra, indicating that cooking has a significant destructive effect on the corn stalks. According to the analysis of the components of steamed straw, the decomposition of hemicellulose into several small molecules leads to an increase in the number of hydroxyl groups, a strong characteristic hydroxyl peak at $3407 \mathrm{~cm}^{-1}$, an enhancement of $\mathrm{CH} 2$ and $\mathrm{CH}$ characteristic peaks at $2926 \mathrm{~cm}^{-1}$. The enhanced characteristic peaks of saturated carbon-hydrogen bonds at -1300 to 1475 $\mathrm{cm}^{-1}$ indicates that large molecules are destroyed, possibly due to COC bond cleavage within or between the molecular chains, because of the relative characteristic peak intensity ratio of $\mathrm{COC}$ at $1162 \mathrm{~cm}^{-1}$ of streamed stalks. Oven-drying stalks should be low as depicted in two graphs. The curves at 1800 to $2800 \mathrm{~cm}^{-1}$ are of opposite heights, which may be due to the destruction of functional groups such as esters, anhydrides and lactones with characteristic peaks between 1710 to $1890 \mathrm{~cm}^{-1}$. The decrease in the corresponding characteristic peaks resulted in an increase in carboxylic acid species, an increase in the $\mathrm{OH}$ characteristic peak of the carboxylic acid at 2350 to $2800 \mathrm{~cm}^{-1}$, which caused the left and right spectral absorption intensities in the two graphs to be reversed and acidity of the steamed stalks increased by acidity test; relative peak intensity at 1450 to $1633 \mathrm{~cm}^{-1}$ was increased, indicating that lignin was also destroyed during high-temperature cooking; relative peak intensity at 1010 to 1100 $\mathrm{cm}^{-1}$ and $898 \mathrm{~cm}^{-1}$ was decreased, indicating that glycosidic bonds between glycans broken and decomposed.

The relative absorption intensity of whole spectrum from enzymatic hydrolyzed corn stalks was higher than that of streamed stalks (Figure 4c). During the $16 \mathrm{~h}$ enzymatic digestion, although sugars of the low molecular weight dissolves into water, the relative quantity of hydroxyl and saturated carbon-hydrogen bonds are still increasing, and due to lignin of only very small amount is lost to the water, and as the carbohydrate polymer was degraded by complex enzyme, more corresponding functional groups of lignin are exposed, so that the relative intensity of their corresponding characteristic peaks increases.

Table 3. Analysis of FTIR spectra of corn stalks by different process

\begin{tabular}{|c|c|}
\hline Wavelength $\left(\mathrm{cm}^{-1}\right)$ & Function \\
\hline $3430-3420$ & $\begin{array}{l}\text { The characteristic absorption peaks of the stretching vibration of } \mathrm{OH} \text {, and } \\
\text { the } \mathrm{OH} \text { stretching vibration associated with hydrogen bonds (lignin) }\end{array}$ \\
\hline 2926 & The stretching vibration of $\mathrm{CH} 2$ and $\mathrm{CH}$ \\
\hline $3000-2500$ & OH stretching vibration of carboxylic acid \\
\hline 1633 & Extending vibration of $\mathrm{C}=\mathrm{O}$ attached to aromatic rings in lignin \\
\hline $1600-1450$ & Stretching vibrations of Lignin and other benzene-containing skeletons \\
\hline $1475-1300$ & Bending vibration of Saturated hydrocarbon-bonded in-plane \\
\hline 1163 & Asymmetric stretching vibration of carbohydrate C-O-C \\
\hline $1100-1010$ & The glycosidic bond vibrations in cellulose and hemicellulose \\
\hline 898 & $\beta$-D-glucopyranoside bond vibration \\
\hline
\end{tabular}


The relative absorption intensity of whole spectrum from fermented corn stalks is lower than that of enzymatic hydrolyzed corn stalks from figure.4 (d), indicating that the reducing sugar containing relatively more hydroxyl groups and saturated carbon- and-hydrogen-bond functional groups is utilized by yeast during fermentation.

\section{CONCLUSION}

According to the tracing analysis of the feed transformation processes of corn stalks through $\mathrm{x}$ ray diffraction, SEM and IR, it was concluded that thermophilic digestion destroyed fibrous crystal markedly, cellulase degraded fibrous crystal
Lignin is lost in a very small amount with longterm fermentation of $55 \mathrm{~h}$. Because of the increase in the total mass after fermentation, the corresponding functional groups of lignin are masked, so that the relative intensity of the corresponding characteristic peaks decreases.

lightly, and fermentation barely reduced fibrous crystal.

The results showed that an in-depth study and improvement of thermophilic digestion are practical ways to increase the saccharification rate and feed yield of corn stalks.

\section{ACKNOWLEDGEMENTS}

The authors are grateful for the support of the Science and Technology Overall Planning for Innovation Engineering Project of the Shaanxi Province, China (No. 2013KTDZ03-01-03) and the science and technology project of Weinan city (No.2017CXFC-27).

\section{REFERENCES}

1. Behera S, Arora R, Nandhagopal N, et al(2014). Importance of chemical pretreatment for bioconversion of lignocellulosic biomass[J]. Renewable \& Sustainable Energy Reviews, 36:91-106. DOI:10.1016/j.rser.2014.04.047

2. Chen, H., Yu, J., Shu, G., \& Zhang, Q. (2009). "Technology for producing protein feed from corn stalk by multi-strain distributional degradation," T. Chin. Soc. Agr. Eng. 25(12), 331-224. DOI: 10.3969/j.issn.1002-6819.2009.12.057

3. Chen, H., \& Zhang, Q. (2008). "Technology for co-degradation of corn stalk by microorganism and enzyme," T. Chinese Soc. Agr. Eng. 24(3), 270-273. DOI: 10.3969/j.issn.1002-6819.2008.3.054

4. Chen, H., Sha MEI, Chunji DAI et al (2018). "Improving fermentation of steamed stalk to feed using Candida utilis and Pachysolen tannophilus". Acta Universitatis Cibiniensis Series E: FOOD TECHNOLOGY. 22(2), 51-58. DOI: 10.2478/aucft-2018-0012

5. Hassan S S, Williams G A, Jaiswal A K (2018). Emerging technologies for the pretreatment of lignocellulosic biomass[J]. Bioresource Technology, 262:310-318. DOI: 10.1016/j.biortech.2018.04.099

6. Huang X J, Ding Y, Liao X L, et al(2018). Microbial lipid production from enzymatic hydrolysate of corn stover pretreated by combining with biological pretreatment and alkalic salt soaking[J]. Industrial Crops and Products, 124:487-494. DOI: 10.1016/j.indcrop.2018.08.030

7. Kojima Y, Takayasu M, Toma M, et al (2019). Degradation of cellulose in $\mathrm{NaOH}$ and $\mathrm{NaOH} / \mathrm{urea}$ aqueous solutions by ultrasonic irradiation[J]. Ultrasonics sonochemistry, 51:419-423. DOI: 10.1016/j.ultsonch.2018.07.030

8. Luo, L., Li, C., \& Yuan, J. (2009). "Optimization of simultaneous saccharification and fermentation conditions for production of bioethanol from steam-exploded corn stover using response surface methodology," Chinese J. Bioprocess Eng. 7(3), 27-33. DOI: 1672-3678(2009)03-0027-07

9. Ma P.,Feng C., Liu H., Yu Z(2018). Effects of Instant Catapult Steam Explosion on chemical structure of corn straw. Journal of Henan Agricultural University,52(1):85-90. DOI: 10.16445/j.cnki.10002340.2018.01.014

10. Ponnusamy V K, Nguyen D D, Dharmaraja J (2019). A review on lignin structure, pretreatments, fermentation reactions and biorefinery potential[J]. Bioresource Technology, 271:462-472. DOI: 10.1016/j.biortech.2018.09.070 
11. Rastogi M, Shrivastava S (2017). Recent advances in second generation bioethanol production: An insight to pretreatment, saccharification and fermentation processes[J]. Renewable \& Sustainable Energy Reviews, 80:330-340. DOI: 10.1016/j.rser.2017.05.225

12. Soest P.J., Rovertson J.B., Lewis B.A. (1991). "Methods for dietary fiber, neutral detergent fiber, and nonstarch polysaccharides in relation to animal nutrition," J. Dairy Sci. 74 (1991) 3583e3597.

13. Shawky B.T., Mahmoud M. G., Ghazy E. A., Asker M. M.,\& Ibrahim G.S. (2011). "Enzymatic hydrolysis of rice straw and corn stalks for monosugars production," J.Genetic Eng. and Biotech. 9(1), 59-63. DOI:10.1016/j.jgeb.2011.05.001

14. Su, D., Sun, J., \& Liu, P. (2006). "Effects of different pretreatment modes on the enzymatic digestibility of corn leaf and corn stalk," Chinese J. Chem. Eng. 14(6), 796-801. DOI: 10.1016/s10049541(07)60014-7

15. Stafilov Trajče, Zdravko Špirić, Marin Glad, Lambe Barandovski, Katerina Bačeva Andonovska, Robert Šajn \& Oleg Antonić (2020): Study of Nitrogen Pollution in Croatia by Moss Biomonitoring and Kjeldahl Method. J. Environ. Sci. Health A 2014, 49, 1402-1408. DOI:10.1080/10934529.2014.928532.

16. Wang CH, Chen WH, Liu HS, Lai JT, Hsu CC, Wan BZ (2018). Process development for producing a food-grade glucose solution from rice straws. CHINESE JOURNAL OF CHEMICAL ENGINEERING Chinese J. Chem. Eng. 26(2), 386-392. DOI: 10.1016/j.cjche.2017.06.004.

17. Wang, Y., Xu, W. (1987). "Quantitative analysis of hemicellulose, cellulose and woody turbulence in lignocellulosic solid matrix," Microbiology China. 1987(02):81-84.

18. Wu, X., An, Q., Dai, Y., \& Si, J. (2016). "Investigating lignocellulose in cornstalk pretreated with Trametes Pubescens Cui 7571 to improve enzymatic saccharification," BioResources 11(1), 2768-2783. DOI: 10.15376/biores.11.1.2.2768-2783

19. Wyman, C. E., \& Yang, B. (2009). "Cellulosic biomass could help meet California's transportation fuel needs," Calif. Agr. 63(4), 185-190. DOI: 10.3733/ca.v063n04p185

20. $\mathrm{Xu} \mathrm{X}, \mathrm{Tu} \mathrm{R}$, Sun $\mathrm{Y}$, et al (2019). The influence of combined pretreatment with surfactant/ultrasonic and hydrothermal carbonization on fuel properties, pyrolysis and combustion behavior of corn stalk[J]. Bioresource Technology, 271:427-438. DOI: 10.1016/j.biortech.2018.09.066

21. Yang, Q., Huo, D., Shi, J., Lin, L., Liu, Q., Hou, Q., Zhang, H., \& Si, C. (2015). "Structural properties of the purified lignins of cornstalk in the cooking process with a solid alkali," BioResources 10(4), 7489-7500. DOI: $10.15376 /$ biores.10.4.7489-7500 